\title{
Living and Dealing with Limited Opportunities: Social Disadvantage and Coping Strategies in Rural Peripheries $^{1}$
}

\author{
Josef Bernard, Anja Decker, Kateřina Vojtî̌ková, \\ Renata Mikešová
}

\begin{abstract}
In this article, manifestations of social disadvantage in peripheral rural settings in the Czech Republic are investigated. Based on the theory of local opportunity structures, the authors identify various aspects of the spatial context that intersect with individual handicaps of people and their households and contribute to poverty and social exclusion. Moreover, coping strategies of vulnerable rural inhabitants are investigated. The empirical analysis is based on qualitative interviews with people affected by various forms of disadvantage, living in three economically weak rural regions. Multiple intersections between individual and contextual factors of disadvantage were uncovered. Limited job opportunities and precarious labour conditions within the local labour market, and the absence and difficult accessibility of services, represent the most important restrictions. Households living in poverty, the unemployed, people with care duties and persons with disabilities have very limited possibilities of overcoming the restrictions of a meager local opportunity structure. Their main problem is their low spatial mobility and temporal flexibility. The result is multiplication of individual vulnerabilities in rural localities. Two types of coping strategies, locality-based and mobility-based, have been identified as partial compensation of the existing deficits.
\end{abstract}

KEY WORDS Rural disadvantage, local opportunity structure, social exclusion, coping strategy, spatial context, Czech Republic

\section{Introduction}

Nad'a is a woman in her mid-twenties. After spending three years on maternity leave, Nad'a became unemployed, as she gave up her job as a kindergarten teacher during her pregnancy. She has been searching for a job without success for one year now. In the rural region where Nad'a lives, a limited number of firms offer jobs, predominantly in industrial plants. She is prepared to accept a manual job in the plants. However, the time requirements of the jobs are not compatible with her child-care duties, as workers are expected to accept both morning and afternoon shifts but the local kindergarten closes at four o'clock in the afternoon and

Sociální studia / Social Studies 2/2016. Pp. 29-53. ISSN 1214-813X.

1 This article is output of a research project "The Socio-Spatial Disadvantage of Inhabitants in Peripheral Rural Regions", funded by the Czech Science Foundation (No. 15-10602S). 
Nad'a has no other child-care help. For the same reason, she does not consider commuting to work over longer distances. Her partner works as a carpenter and usually spends weekdays on construction sites. Nad'a is living on the edge of poverty. Moreover, she finds the local offer of consumer goods and services unsatisfactory. She misses opportunities for cheap shopping and affordable leisure time activities. From time to time Nad'a considers moving, but she stays within the locality because of her partner. She feels increasingly trapped in a situation that does not seem to offer a good outcome. She states: "We are going along this path, but I do not know where we're going, as there is really no vision of the future".

Nad'a's story is illustrative of an accumulation of diverse life circumstances that contribute to feelings of powerlessness and various forms of social disadvantage. However, her personal situation cannot be understood only from an individualistic point of view. She lives embedded in a rural locality that defines many of the constraints and opportunities that form the complex circumstances of her life. Nad'a's life is certainly not entirely determined by her local milieu. However, this milieu forms an important context that intersects with individual traits and structural forces, which together influence her social position, her choices and feelings, and result in poverty and social exclusion.

Spatial effects on various forms of social inequalities have usually been investigated in urban settings with high levels of residential segregation that result in spatial concentrations of poverty in specific urban neighbourhoods. However, in many countries, levels of rural (non-metropolitan) poverty exceed urban levels (Fisher 2005; Shucksmith et al. 2009; Slack 2010; Spoor 2013). Moreover, rural areas are highly heterogeneous concerning income levels, remoteness and concentration of poverty. The considerable extent of rural poverty is an important justification for research into its specifics. Another justification is based on the observation that rural experiences of disadvantage frequently differ from those in urban areas, relate to other social categories and can have different causes and different solutions (Hodge et al. 2000; Kearns et al. 2000).

In this article, we investigate the spatial effects of social disadvantage in Czech rural settings. We first summarize the theoretical debate about limited opportunity structures as a factor influencing rural disadvantage and related coping strategies. Subsequently we present the results of a qualitative empirical study of disadvantage experienced by inhabitants of selected peripheral rural areas in the Czech Republic. We conducted interviews with people at risk in terms of financial constraints, labour market access, mobility and social isolation, and observed how their narratives about the problems they face and their coping strategies reflected various territorial aspects and the local context of their residence. In doing so, we aimed to identify the territorial effects that contribute to or modify various forms of disadvantage and strategies of coping therewith in the observed regions. The article seeks to enrich the theoretical and empirical debate on social disadvantage and coping strategies by stressing the importance of the spatial context and the intersections between contextual effects and individual handicaps. Moreover, the article examines disadvantage in comparatively less frequently studied middle-European peripheral rural areas. 


\section{Local Opportunity Structure as an Explanation of Rural Disadvantage}

Even if reflections on local opportunity structures still lack a comprehensive theory, a broad range of theoretical propositions concerning opportunity structures have been formulated and empirically analysed. The basic starting point for theoretical considerations about local opportunity structures is the fact that the physical space inhabited by people and filled with their institutions is an arena offering various opportunities and constraints for the people occupying it and for their activities. In this sense, Beetz states that the living conditions of people are characterised by the social, political, economic and cultural environment, which offers specific opportunities to participate in desirable activities and goods (Beetz 2008: 8).

Rural areas, often operationalised as non-metropolitan regions, have repeatedly been described as territories characterised by a limited opportunity structure, whose inhabitants make use of a limited number of economic opportunities and face specific obstacles in accessing them (Tickamyer and Duncan 1990; Cloke et al. 1995; Philip and Shucksmith 2003; Weber et al. 2005). In some studies, the effect of limited opportunities in rural areas has been described as an independent contextual factor contributing to increased levels of poverty. Cotter (2002) argues that limited opportunity structures in US non-metropolitan areas expressed by labour market ecology affect both the likelihood of being poor and the degree to which employment reduces a household's chances of falling into poverty. In his view, increased levels of rural poverty can be explained apart from household-level characteristics as a consequence of labour shortage and the dominance of low-pay job sectors in rural areas. A number of other studies have confirmed that the job market in rural areas is biased in favour of lowpay jobs (Slack 2010; Lobao et al. 2008; Shucksmith and Philip 2000). Moreover, it has been argued that the supply side of the labour market is another important predictor, as finding and retaining a job is hampered by specific constraints and requires increased costs for employees in rural areas, due to worse infrastructure and transport costs (Phillip and Shucksmith 2003).

Several authors have argued that deficiencies in opportunity structures in rural areas do not impact all inhabitants in the same way. One of the most striking features that distinguish the vulnerable groups is the level of individual mobility. People with mobility constraints due to age (young and old), poverty, disability or lack of a driving license are particularly exposed to deficiencies in local opportunities (Philip and Shucksmith 2003; Temelová et al. 2011; Shergold and Parkhurst 2012). People with low qualifications and limited employability for distant, well-paid jobs represent another category trapped within the low-opportunity local circumstances (Shucksmith 2004). Moreover, women have been found to experience higher levels of disadvantage due to rural labour markets offering rather traditionally male jobs, limited opportunities for child care and a more traditional division of labour within households (Brown and Shafft 2003; Phillip and Shucksmith 2003; Plazinic and Jovic 2014 ). All the above-mentioned findings are manifestations of a cumulative causation of disadvantage in rural areas. Inhabitants with limited resources are more likely to depend on the local opportunity structure that further contributes to their disadvantage.

The concept of contextual effects resulting from the limited opportunity structure of rural areas has been further used to explain the life experiences of rural inhabitants above and beyond their labour market positions. During the 1990s and 2000s several studies focused on social disadvantage and social exclusion in rural areas (Shucksmith 1994; Shucksmith and 
Philip 2000; Philip and Shucksmith 2003; Commins 2004; Reimer 2004). Commins argues that using the concept of social exclusion enables one to shift attention from income-related poverty to the multidimensional disadvantages which many rural inhabitants face (Commins 2004: 68). In rural studies, the conceptualisation of social exclusion as a malfunctioning of the integration mechanisms that interconnect individuals with society and allocate resources has been used repeatedly. These integration mechanisms have been classified in various ways, as market relations, bureaucratic allocative relations, family and friendship relations and associative relations (Shucksmith et al. 2000; Meert 2000; Commins 2004; Phillip and Shucksmith 2003; Reimer 2004). The attention paid to various integrative mechanisms not only builds on Polanyi's argument that there are various modes of economic integration beyond market exchange that are used to allocate resources in society (Polanyi 1944), but it also extends the focus of the analysis beyond resource allocation to the broader issue of social integration, thus incorporating issues of sociability, participation and power into considerations on local opportunity structures. Parallel to employment and job accessibility, which are conceptualised as specific structures of opportunities, the functioning of other integration mechanisms also requires the existence of diverse local facilities and an infrastructure which form elements of opportunity structure - for example, schooling, transport infrastructure, social networks and various social services have been described as important elements of such structures.

Various opportunity structure deficiencies have been discovered in rural areas, which impact integration mechanisms and contribute to social exclusion: low accessibility of public services, especially educational institutions and child-care, and their lower quality (Roscigno and Crowley 2001; Roscigno et al. 2006; Alston and Kent 2009; Shucksmith 2004; Sikora 2007); unsuitable public transport and limited mobility opportunities (Philip and Shucksmith 2003; Gray et al. 2006; Plazinic and Jovic 2014 ); lack of political representation (Philip and Shucksmith 2003); and lack of social services and infrastructure for affordable shopping (Meert 2000; Spoor 2013). In remote rural communities a lack of familial support has been observed (Osti 2010).

Some studies consider local opportunity structures from the viewpoint of community theory. Community social structures have been identified as factors that allocate opportunities to various categories of community members or that pose barriers for them. Duncan (1996), who studied US rural communities with high levels of persistent poverty, found that the composition and relations of social classes within rural communities shape opportunities for social mobility. She found the highest levels of persistent poverty in communities with a rigid two class system of a small minority of agricultural employers and a poorly paid labour force. In such a local social structure, the minority of "haves" were able to prevent the other inhabitants from using potential channels of mobility. Bird et al. (2002: 2) argue that in (formerly) agricultural areas, remote from dynamic social change, the development of an active civil society able to challenge the historic holders of power is less likely. The nature of local social networks has yet another impact on social inequalities. In relatively small communities, where there is a higher level of social control, the position of people within local social networks is an important factor in seeking employment, mutual support or even allocation of social services. Accessing jobs within limited local labour markets depends crucially on local acquaintances and one's reputation within the local community (Alston et al. 2009; 
Shucksmith 2004). In summary, the historically established social structure of rural communities has not only been considered responsible for limiting individual and collective social mobility, but has also been described as a milieu with its own rules for allocating support and resources, which therefore creates specific routes into and out of social exclusion.

\section{Rural Communities and Coping Strategies}

The idea of local opportunity structures can be used productively also in attempts to explain the strategies which rural inhabitants use to cope with various forms of disadvantage. We define coping strategies in a similar sense as Meert, who conceptualises survival strategies as "individual's or household's intentions to battle macro-social obstacles that obstruct their intentions and goals" (Meert 2002: 327). However, in contrast with Meert, we understand coping strategies not just in an economic dimension, but we expand the scope of actions described by the term in order to include all the activities intended to overcome the various forms of disadvantage resulting from malfunctions of societal integration mechanisms as described above. Within this concept, economically motivated strategies are complemented by strategies aimed at achieving other goals, such as maintaining social contacts, securing transport possibilities, attaining adequate educational or health services and participating in preferred leisure activities.

Meert highlights the important fact that even strategies used to cope with disadvantage need certain local opportunities (Meert 2000: 331). Informal work as an important coping strategy for people excluded from the official labour market needs demand for informal labour, strategies used to reduce living costs require adequate opportunities for inexpensive shopping or informal exchange of products, etc.

Three repeatedly highlighted aspects of rural areas could potentially have specific effects on the strategies used. First, the tradition of self-supply and housing conditions that enable gardening and small-scale farming can form the basis for an alternative economic strategy. Especially in the Central and Eastern European countryside, self-supply remains an important activity for a significant part of the population. However, its role as a survival strategy remains controversial (Albert and Kohler 2008; Jehlička, Kostelecký and Smith 2014). Second, dense networks of social and familial relations can serve as a potential safety net. Of course, such networks have dual aspects. On one hand, they offer alternative income and support strategies and play an important role in social integration, whilst on the other hand they can effectively exclude individuals who do not conform to local rules or who merely lack important ties within the locality. Third, the absence of social services and other "survival infrastructures" such as charity initiatives, low-priced shops or a developed public transport system disallows their use and limits the range of coping strategies (Meert 2000; Spoor 2013).

Outmigration plays a specific role amongst coping strategies. As migration theory reveals, migration flows are often driven by regional labour market activity, thus reducing the spatial mismatch between people and labour demand (Hämäläinen and Böckerman 2004). Outmigration can therefore be an important individual strategy to deal with limited opportunities. However, for the most vulnerable groups migration often doesn't represent a viable coping strategy due to limited access to the housing market. It has been repeatedly found that poor people are at risk of becoming trapped in deprived areas, or poverty pockets (van 
Kempen 1997). In some cases, peripheral rural localities have even become destinations for urban poor people due to inexpensive rental housing (Fitchen 1995).

\section{Opportunities and Disadvantage in the Central and Eastem European Countryside}

Most theoretical considerations on inequalities, poverty and social exclusion in rural areas have been derived from research conducted in the UK and the US. Rural disadvantage in continental Europe, especially in Central and Eastern European countries remains rather undertheorised and the existing research is usually descriptive in nature. However, Shucksmith et al. (2009) found that urban-rural differences in Europe are especially imbalanced in favour of urban areas in the poorer European countries in the south and east. In these countries, rural areas have a much lower level of perceived welfare and quality of life compared with towns, and are characterised by much higher levels of disadvantage. The existing findings on rural development in a number of these countries, namely in those that experienced post-communist transformation, indicate that the concept of limited opportunity structures can be productively used also within their context. The post-communist transformation was characterised by massive economic restructuring that, amongst other factors, strongly affected agriculture. Intensive agricultural labour shedding impacted many rural regions in the 1990s (Petrick and Weingarten 2004). As large state farms and agricultural cooperatives during communism not only offered jobs in rural areas but often provided various services and organised local public life, their dismantling was in many cases experienced as a sharp and rapid limiting of not only economic local opportunity structures, which were hard to compensate for (Haukanes 2004). In areas that were not able to compensate for the job losses by other forms of labour, particularly in remote areas with limited possibilities for commuting, a severely limited opportunity structure stabilised. During the years of further development, rural areas in Central and Eastern Europe faced a number of challenges that contributed to their diversification. Increasing but very uneven involvement of rural areas in the global economy diversified rural labour markets. An important distinction in most CEE countries may be drawn between successful areas, predominantly with good access to cities, and peripheral areas trapped in vicious circles of population loss, economic decline and shedding of services, which together can be interpreted as a hollowing out of several dimensions of local opportunity structures (Musil and Müller 2008; Penzes 2013). EU accession further altered the developmental trajectories, first as a result of the common agricultural policy and structural policy of the EU, and second as a driver of population change due to outward migration in some of the newly acceding countries.

The second specific of post-communist countries is the comparatively limited extent of urban deconcentration and suburbanisation. Western Europe has experienced a reversal of internal migration trends since the second half of the $20^{\text {th }}$ century, the prominent features of which were a gradual deconcentration of towns, expansion of metropolitan areas and migration into previously rural regions. This trend changed many rural localities and contributed to their transformation into predominantly middle-class communities. The influx of the middle class went hand in hand with broadening opportunity structures and the disappearance of the former agriculturally based community structure. This process represents a big 
part of what is called the transformation towards rural post-productivism (Cloke and Godwin 1992). In communist countries these trends were essentially blocked until the end of the 1980s. During the post-communist transformation process, suburbanisation and urban-rural migration started only gradually; however, for now, the extent remains limited and has not resulted in a balancing of urban-rural differences in the same way as in Western Europe.

The Czech countryside shares some similarities with rural areas in other CEE countries and differs in others. The main specific is its high level of industrialisation and the limited role of agriculture in providing rural jobs. Moreover, limited outmigration from the Czech Republic and a strong population deconcentration that started in the 2000s resulted in net population gains in most rural areas. However, rural development in the Czech Republic is highly diversified and important parts still face problems such as depopulation, shortage of qualified employment opportunities, poor transport access, underdeveloped civic infrastructure, and declining civic life (Ouředníček et al. 2011; Temelová et al. 2011; Musil and Müller 2008), which together can be described in terms of limited opportunity structures that exceed the economic sphere and also negatively impact other integration mechanisms.

\section{Methods}

Our study of rural disadvantage and the corresponding coping strategies in the Czech Republic is based on qualitative interviews with rural residents affected by various forms of disadvantage, living in three peripheral rural regions. All the regions were selected to represent localities with above-average levels of unemployment, population decline, limited education, predominance of low-skilled labour and limited accessibility to economically viable cities. The Žihle region in the western part of the Czech Republic, the Hanušovice region by the Czech-Polish border in the Jeseníky Mountains and the Brumov-Bylnice region by the Czech-Slovak border were selected as study sites. Altogether about 12000 people live in the regions studied, but their population is in steady decline (approximately $8 \%$ population loss over the last 20 years). The map in Figure 1 illustrates the location of the study sites together with local unemployment levels in Czechia.

We deliberately searched for respondents facing various forms of disadvantage related to financial constraints, labour market access, mobility and social isolation. In total, 19 interviews were conducted with individual respondents or several household members. Of these, nine persons were unemployed or some of their household members were unemployed, four were senior citizens living on pensions, eleven had no access to cars or no driving licence, and five were mothers on maternity leave or economically inactive housewives. Six respondents faced serious health problems or cared for household members with health problems. Some respondents were exposed to an accumulation of diverse forms of disadvantage.

The interviews focused on life trajectories, everyday activities, experience of disadvantage and corresponding coping strategies. In the subsequent analysis, we concentrated on the reflections on the various problems the respondents face and cope with and on their intersection with the local environment, its opportunities and constraints. The analysis uncovers the positions the various territorial aspects occupy in the lived experience of our respondents 
and how they modify the perception of disadvantage and the various strategies used to adapt to or overcome it.

Figure 1: Location of the study sites and local unemployment levels in 2014

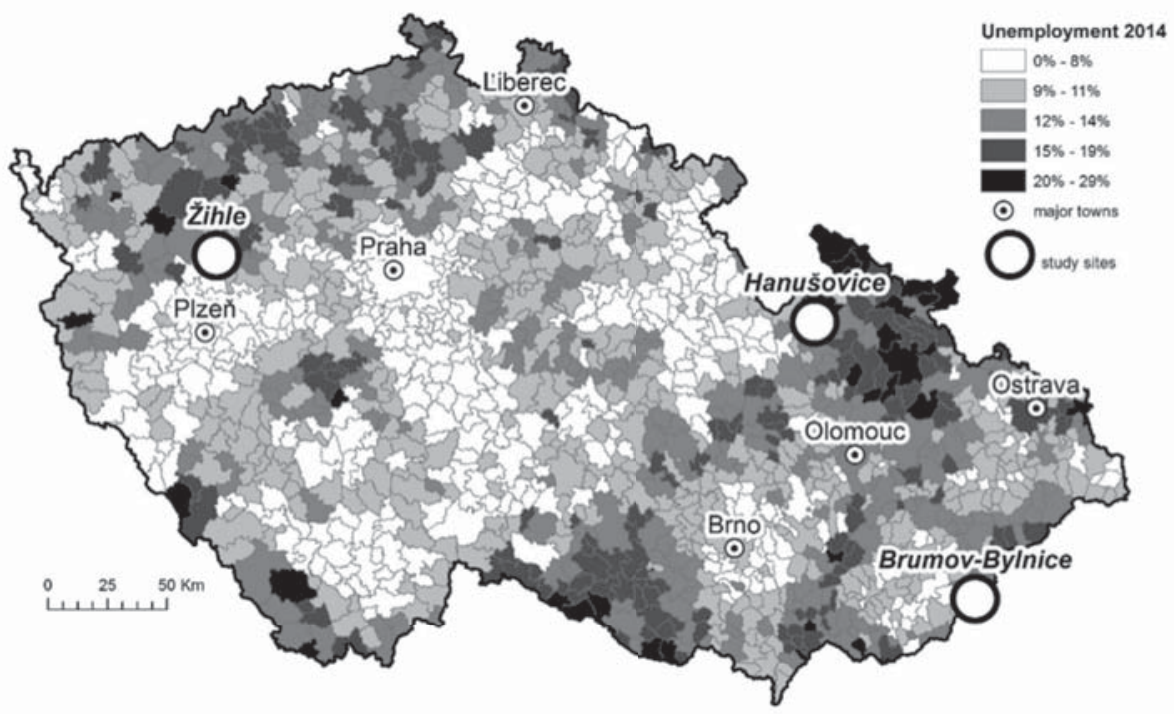

Source: Unemployment data - Ministry for Labour and Social Affairs

\section{Expenience of Disadvantage in Rural Penipheries: Work, Household, Mobility}

Drawing on our empirical material, we elaborate three sections analyzing how the respondents experience and describe disadvantages concerning their opportunity structure. Whereas most respondents state that they would not consider moving away from their village and see many advantages of rural life, such as quiet, safety and good relations with neighbours, they argue that what makes their lives complicated and limits their scope of action is that many things they consider important are either missing completely or are difficult to attain, so that they need to put a comparably large effort into gaining access to income and food, health and education, social participation and leisure-time activities. Disadvantage in specific lives thus reflects the individual handicaps of people or households intersecting the limited structure of opportunities within the locality. Within this shared interpretative framework of absence of and distance from opportunities, highly diverse understandings of what is lacking and what constitutes distance become apparent. Firstly, there is a high degree of variability concerning which specific opportunities are regarded as important. Secondly, the physical distance that makes something "hard to reach" or "out of reach" is highly relative; some respondents describe it as a tremendous effort to travel to the neighbouring communities whilst others are highly spatially mobile, thus referring to entirely different distances and contexts when reflecting on their opportunity structure. 
Work

It's simply a fact that these days it's all about money, money's simply what drives the time we live in, so work's important and then everything's based around that and comes out of it, and if I know that my boyfriend has such and such a job opportunity then I certainly won't drag him away from here. (Hanušovice region)

The respondents attribute a high value to work as the main source of income, despite the fact that many of them have had problems finding stable employment or experienced very precarious working conditions. The stress caused by the lack of one's own income can lead to a willingness to take a job which under more favourable conditions would not come into consideration, to commute every day or work for a longer period of time away from home.

If they speak of their job or the availability of work within the locality and surrounding area, they refer to low earnings; seasonal, physically demanding (agriculture, construction, industry) jobs with the necessity of working in shift operation or outside in all weather (i.e. in a forest or quarry); jobs with a high employee turnover (supermarkets); and work via employment agencies, generally with an insecure employment contract. Respondents of middle age and older describe the gradual decline of localities which, in their view, provided far more job opportunities in the past. They mention the closure or bankruptcy of specific medium to large enterprises which employed a substantial proportion of the population, and which were predominantly operated by the state.

The absence of (better paid, less demanding and stressful) work within the localities was mentioned frequently by the respondents as an immediate cause of their own difficulties, or those of people within their close surroundings. Individual disadvantage on the labour market, e.g. a low level of qualification, long-term absence from the labour market due to childcare, advanced age or lack of social contacts, adds to the difficulty of the situation, which without social support can be irresolvable.

Commuting to work to larger towns situated several dozen kilometres away is considered one of the few opportunities for securing a better income within the locality, for which it is necessary to take into account transportation costs. However, many commute even to perform labouring jobs in factories, where the work is physically demanding, for a low wage and in shift operation.

Commuting far away to work, or spending a long time away from home due to work, is practised in some families as a method by which to secure an income for the family or to pay for the reconstruction of their home without taking on debt. However, the absence of one partner for most of the day, or even longer periods, can cause conflicts between the partners or lead to problems in everyday household management. A job in which the husband spends weekdays away from home and comes home only for weekends was experienced very negatively by a woman with a small child living in a small village in the Žihle region. Feelings of loneliness and difficulties in organising everyday tasks without a driving licence led the woman to insist that after the completion of the reconstruction of their home and in preparation for a second child, her partner find work in their place of residence, even if it was more poorly paid. In another case, a man who had worked for a long period away from home 
in the construction industry identified his frequent absence from the home as the reason why his partner had found another man, leading to the breakup of his family with two children and finding himself without a roof over his head.

A fundamental obstacle for a range of respondents is the difficulty of managing the timing of available job opportunities. The problem is not only the need to commute to work and the attendant demands on time, but also the wide spread of shift operation in local industrial firms. Shift work is more difficult to perform when caring for other household members, especially if there is a lack of support within the extended family. With regard to the opening hours of nursery schools or the lack of other facilities, the chances of those who care for children (in our sample only women) or for the sick (in our sample both women and men), and who at the same time do not have access to such support, are perceived as small.

Faith in the possibilities of the employment office to help with finding employment was low amongst the respondents. In a number of cases the respondents rather appreciated the conciliatory approach of the job centre workers towards the long-term unemployed within the locality. They did not excessively "hound" registered claimants, and took into account the problems which families or individuals living in remote areas experienced with commuting to work. For example, during the summer the employment office reduces the frequency of visits from one visit per month to one visit per two months. On the other hand, they also show a certain effort to encourage the unemployed to gain extra earnings or to take on subsidised community work, which, however, is merely a deferral of the problem of unemployment or a temporary solution before retirement. Some respondents further detailed hard working conditions in local firms and experiences with inconsiderate treatment.

For example, several women aged over fifty spoke of the considerable pressure to be productive in factories. They presented an image of themselves as drudges who were used to hard physical work all their lives. Nevertheless, the setting of productivity norms in conveyor belt production is such that at their age the women are unable to keep up, and are aware of the fact that the labour market has no interest in them. They describe how the regular tempo of the production line is even higher than that represented in order to impress visitors or the owners. In their view, physical labour is by its nature for the younger and more physically able, who are able to manage the fast pace. Younger women work in the factories, but these women have to address the problem of three-shift operation if they have children. The strict regime of the female labourers is illustrated by an episode in which they described the factory as a dehumanised place which was inconsiderate towards their natural human needs. Under the strict working conditions, permission for a working mother to telephone her ten year old sons, who are at home alone because there is nobody to look after them, represents an act of great benevolence on the part of the manager.

\section{Household, Services and Social Relationships}

On the other hand there are a lot of things that are missing here just because I'm a mother, like doctors just for children, I don't have such opportunities here to go to doctors, and here there's no option to go out with the kids, for example a cinema or a playground, there's simply not much 
around here and when there is then not many people appreciate it, so they don't treat it as well as they should, and only the absolute minimum holds out here, so in that respect it's pretty difficult. (Hanušovice region)

Several of our respondents rank amongst people who, due to their limited access to the labour market, age or care for family members, spend the majority of their time within their place of residence or experience various mobility constraints. The limited choice or absence of local services such as shops, healthcare, education, cultural life or activities for children and adults form the context of the management of the everyday lives of the respondents, which for a large number of them represents a problem in securing the requirements of household members.

According to the narratives, the limited offer of services forces especially those with limited mobility to reduce their requirements and be satisfied with what is available, such as a single shop with high prices and a small range of goods. Larger shopping trips to the city in connection with a wider selection of shops, goods and lower prices are infrequent due to the need to travel, which is calculated into the price. If no car is available, the shoppers must carry heavy bags.

The offer of cultural and leisure activities for children and adults within the localities is perceived as limited, and does not always meet the expectations of the respondents. This depends on whether the character of the offer suits them, whether they are well integrated in the locality and whether they can afford it financially. Some mentioned that they have no place where they can "go out for a drink", which isolates them in their houses or flats. Some respondents spoke of their day-long confinement around their house, family, and work, but others complained of their boredom and lack of leisure opportunities.

For example, maybe once a month a woman wants to get out and have a day for herself, to let herself go a bit, maybe have a beauty treatment, that doesn't exist here, and if you find anything like it round here the prices are absolutely unaffordable for the people who live here, and also I don't have anywhere I can just go and sit down and have a drink, some cultural activity, there's never any cinema or anything like that. (Hanušovice region)

When reflecting on their opportunities for leisure time activities, some respondents again refer to an earlier time as more prosperous, or they make comparisons with better conditions enjoyed by their friends and relatives living in cities. In some localities they feel a lack of community activities, active leaders and younger people who would be capable of motivating others. In one interview, holiday home owners were perceived to have a significant role in organizing free-time activities in the community. However they spend their time in the area only temporarily.

The quality of life is also influenced by quality of dwelling, which depends on the financial realities of the respondents, their assets and the local housing market. Due to the problematic financial situations of their households, a range of our respondents made use of the cheapest possible form of accommodation, namely rather unsuitable municipal flats, rented accommodation and boarding houses. Whereas within the popular discourse, life in rural areas is linked with an image of detached houses each with a garden and owned by the residents, a large proportion of our respondents did not have the opportunity to live in such 
accommodation. The conditions of their domicile were in large part considered unsuitable. They complained of the low quality of their accommodation and the uncertainty of extending their rental contracts, which makes accommodation an emergency choice. In some cases, flats were in poor condition. Rented accommodation or accommodation in boarding houses was also mentioned within the context of tense relations with neighbours and a disadvantaged social environment. The respondents in a municipal flat described unpleasant feelings resulting from a lack of privacy from their neighbours, constant supervision, envy and intentionally spiteful and obstructive behaviour.

The availability of healthcare in the geographical area of the respondents' residences is limited, and virtually always requires commuting. According to the narratives, the situation is complicated by the closure of certain departments and the centralisation of health care in larger towns, and the distribution of specialised doctors' offices for children and adults. People obtain only limited access to information about changes of opening hours or doctor's leave, and a journey to deal with health problems may thus result in a waste of both time and money. In one of the interviews we encountered a situation in which the family budget was substantially burdened by the fact that the woman had to visit a specialist in a regional centre four times during the course of one month.

According to the testimonies of the respondents, the decision regarding choice of school is influenced far more by the route of the school bus or the price of commuting than the quality of teachers, the offer of extra-curricular activity clubs and satisfaction with the school itself. Even securing basic education for children may mean the need to commute and expend further finances for families if there is no school available within the vicinity of their residence. In the case of secondary schools and universities, commuting is absolutely essential. One of the options is for a child to live in a hall of residence, which means further expenditures for the family, and as a result, in the case of financial problems a family will factor this into the choice of school, or consider the option of the child living with relatives who have moved to town.

Mobility

You have to travel everywhere, to go shopping... you have to travel to the doctor's, the children have to commute to school, yeah... if they have any activity club then it's all about travelling there and back again... (Hanušovice region)

Life on the rural periphery brings with it a pronounced need to commute regularly. The degree of individual mobility has an influence on seeking employment, on the accessibility of various types of services, and on the quality of life within the locality. All kinds of limitations on individual mobility thus represented a fundamental aspect of perceived handicaps. Overcoming distances in order to obtain employment and services requires considerable expenditure of time and/or financial resources. In order to overcome distances the respondents use various means of transport, ranging from walking and bicycle to public and private transport. In our diverse sample we spoke to people who own their own car, but also to those who have never owned a car, and who did not have or had lost a driving licence. Some 
consider obtaining a driving licence to be financially challenging, whilst other obstacles to driving include health complaints, as well as old age, fear of driving, or loss of a driving licence. Although many respondents regard ownership of a private car (or even two) as essential in their situation, due to their low incomes or indebtedness they cannot afford to buy, operate and repair a car.

Public transport is a public service upon which individuals or whole families without a private car or driving licence are dependent to a considerable degree (alternative strategies will be dealt with in the following section). As in the case of work, the narratives reflect the widespread feeling amongst rural inhabitants that transport accessibility to their locality is deteriorating over time. They recall the closure of railway stations and services in favour of bus transport, the frequency of which is in decline. The running of the local buses does not suit all the inhabitants; for example, buses do not run later in the evenings or at weekends.

Buses serve certain more remote communities only very sporadically. A woman from a remote community explained that she was unable to take employment in a faraway town due to the limited transport connection, since she would be unable to reach work on time. She is dependent on the morning bus by which her children travel to school and kindergarten, and has to ensure that they are taken to and from school.

For the less mobile who are not integrated into social networks, life outside of town is structured according to transportation links. For a family which is dependent on public transport, a change of the bus timetable thus requires a reorganisation of the running of the household. Another considerable disadvantage for low income families may be the increased costs of travel to school for children, which would not be required in a town or municipality with a primary school.

The uncertainty of transportation represents a source of stress for some inhabitants. For example, respondents have encountered situations in which bus service is cancelled in winter due to ice on the roads. They have also experienced a reduced number of services and a lack of connections or connections which exist only on paper. Whilst the timetable says one thing, the buses do not wait for one another in practice, with the result that travellers are stranded for long periods of time with no possibility of reaching their destination on time.

What could we wish for? Better accessibility to the other villages, to get somewhere. So not to be dependent on something, so you can get make it on time, just get on the bus and go somewhere. To make some other train on time. Simply not to have to worry, to be constantly checking everything. (Žihle region)

However, we cannot say that problems with public transport are universally experienced by all who do not have a car. It depends on the habits and daily routines of the residents and place of residence - life in a remote settlement is understandably more complicated in this respect than life in close proximity to a rural town centre. Although a woman living in a small rural town may not be able to drive due to illness, she does not consider it a problem. She explains that she has been accustomed all her life to using public transport, just like her parents, who also did not have a car. She is able to obtain the necessary information in order to travel to her required destination. Even living alone outside of town need not represent a problem, as in the case of a physically able middle aged man who prefers living in a tranquil 
environment away from civilisation. He travels everywhere by bicycle, which is his hobby and main means of transport, and uses rail connections or hitch-hiking only as a supplement.

The remoteness and poor transportation accessibility of certain communities lead to concerns in cases when quick medical attention is needed. Two women whose close relatives found their lives in danger spoke of the closure of nearby emergency services and their doubts that the ambulance service could arrive in time.

\section{Dealing with Absence and Distance: Locality-based and Mobility-based Strategies}

Through in-depth interviewing, we were able to identify at least two sets of strategies for dealing with the absence and distance of opportunities as described above. Firstly, we take a look at locality-based strategies. We understand these strategies as practices that are applied in the immediate surroundings of the respondents' place of residence. Focusing on local work, subsistence production and economising practices, we ask how the respondents make use of locally accessible resources to create opportunities and widen their scope of action. Secondly, we investigate mobility-based strategies. We understand this second bundle of strategies as practices that enable the respondents to travel physically to access various resources, goods and services. With particular attention paid to respondents with low individual mobility, we show how opportunities are accessed through asking for lifts and economising on travelling.

Naturally, the differentiation between locality-based and mobility-based strategies is an analytical distinction. In practice the respondents combine both strategies to manage their everyday lives, whereas the balance between both sets of strategies varies substantially. However, the analytical distinction between locality-based and mobility-based strategies proves to be a useful framework in order to gain a deeper understanding of the scope of measures various disadvantaged groups use to cope with (perceived) absence and distance.

\section{Locality-based Strategies}

Income strategies

The lack of stable jobs offering income considered adequate, combined with the limited individual mobility of some respondents, posed significant barriers to respondents' livelihoods. Hence, in cases where they did not find stable employment in their places of residence, an important source of income was social security benefits, such as social welfare, care allowances, disability benefits and pensions. Apart from this, the interviews revealed how the respondents made use of various resources and social networks in order to find alternative earning possibilities within their immediate surroundings. For example, the rural tourism sector offered opportunities for casual work in local restaurants or hotels, and local farmers provided opportunities to help with agricultural labour. As the following example demonstrates, such work could depend on close personal contacts and friendships; it was also not necessarily compensated with a salary, but could be paid in kind: 
Well take me for example, I've got this friend. You know the ones, who have this farm. So in the autumn we go and pick potatoes. And so for example I get free potatoes from her for the whole winter, because we help pick them, we help her to sort them, so like as a reward for that we have for example potatoes for the whole winter. (Žihle region)

Good local social integration and a positive reputation, access to networks and relationships of trust with neighbours and the municipality created opportunities for casual earnings:

Yes, actually a lot of people here work in the forest, yeah. They prepare wood for the winter, then those kind of jobs. Or maybe pile up coal. And these are just basically people who help someone this way, and yeah, it's a way for them to earn some cash. (Brumov-Bylnice region)

Both quotes illustrate that many local casual earning opportunities involve physical labour. Less common were strategies of manual (e.g. folding gift bags or making tools) or digital work from home (e.g. conducting opinion polls via phone or writing articles). Viewed together, a significant number of respondents were able to generate parts of their income without travelling, whilst at the same time most local earning opportunities that were accessible for our respondents must be considered highly precarious, as the work was either undocumented, poorly paid, unreliable, physically demanding and/or based on self-employment.

A somewhat specific local income opportunity is employment with job creation schemes and in subsidised workplaces. Even though these positions are temporary and poorly paid, they were considered highly attractive by respondents with limited mobility or other difficulties accessing the labour market, viewed sometimes even as the only accessible socially ensured possibility of employment: "Yeah, but I'm satisfied. The mayor promised me that she'd take me on, because these days nobody else wants us. We're more than fifty-eight years old" (Brumov-Bylnice region).

Employment via job creation schemes involved comparatively favourable working hours, often with flexible working regimes and - in comparison with undeclared or occasional work - it created a prospect for low but stable income. Frequent expressions of hope to be again employed in a job creation scheme, after completing the compulsory "waiting time" in registered unemployment, along with references made to the non-transparent or unfair rules for participation in such schemes, are further evidence that this form of local employment is highly sought after by a certain section of the rural population. With regard to the importance ascribed to local job creation schemes, it seems relevant to explore further this field of employment policy, which currently appears highly dynamic with respect to the growing possibilities offered by national, regional and EU-funded employment programs.

Considering the range and diversity of local earning and income opportunities, another strategy is to combine several formal and informal possibilities of earning income. In the following example this included writing articles for web pages:

I've got it by way of the internet. I find a theme, work on it till it's broad enough and then send it, like. So I earn an extra few hundred crowns a month, so it's not as if it's a main source of income. The main source of income's what you call social security benefits, why not admit it, from the job centre. Just now I met Mrs. P.(...), we worked in R.L.(...) [a subsidised workplace]. That was also 
like via the job centre, something like the first job I'd done for six months. Otherwise I basically don't work, and my main income... Plus a bit of moonshine that I sell, that I make sort of unofficially, so I don't have to pay consumer tax, I also get a bit of income from that. (Brumov-Bylnice region)

In this example income is produced through a mix of social benefits, casual earnings through digital work, selling self-produced alcohol and temporary employment with a job creation scheme without the need to travel far. In this case, yet again, social networks emerged as a precondition for most of the respondent's income opportunities: for example, he uses his neighbours' internet connection to send the articles he writes for the websites. When he felt under pressure from the job centre to join a job creation scheme, he contacted a friend who worked in a social institution, and was employed there. He describes this work as very favourable with regard to working hours. Furthermore, it was situated in a neighbouring community and for him was accessible by bicycle.

\section{Subsistence production and economising practic es}

For all respondents, generating income (through paid work or various social benefits) is the dominant means of securing their livelihood. Nevertheless, our interviews reveal that a certain section of the respondents invest a considerable amount of time in strategies based on subsistence production and economising, making use of the immediate surroundings of their flats, houses and properties. For example, it was common for the respondents to prepare their own firewood, supplying themselves formally and informally from local resources. Some respondents used personal contacts with local forest rangers to get hold of wood for very low prices, others cut deadwood in a nearby forest or bought it at a discount from local timber-processing companies. However, the wood was not bought or prepared "ready to heat", but chopped at home, which was regarded as an important strategy to save money. Whereas kitchen gardens were relatively common for supplying respondents with vegetables and fruits, we only rarely encountered the strategy of keeping live-stock.

Subsistence production and economising strategies were also linked to house and property ownership. Apart from saving on rental costs, those respondents who owned their homes were able to decide more independently on the aspects in which they preferred quality and comfort and in which they were willing to compromise to enable savings. For example, we encountered strategies to defer renovations and repairs, to heat only sparingly and to use water from their own wells. The interviews also showed the relevance of home storage rooms and workplaces. For example, when asked about their food purchasing strategies, home-owning respondents referred to their cellars, pantries and freezers as important preconditions for saving. Storing food was important in order to reduce the frequency of shopping trips, thus saving time and travel costs, and to reduce food costs, as they could buy more discounted goods on a single shopping trip. Storage space was also a precondition for being paid in kind, and thus relevant to local income production. The linkage between food purchasing and food storage within economising practices well demonstrates how locality-based and mobilitybased strategies are interconnected.

However, the prevalence of subsistence production and a do-it-yourself mentality cannot be explained solely by means of economic considerations, and should not be regarded as strategies adopted only under conditions of economic shortages. Rather, these must be 
understood as practices with multi-layered meanings, including their relevance for social integration, identity, routines and self-sufficient lifestyles. The following quote well demonstrates this multiple relevance of subsistence production:

The disadvantage is that it's extremely long, an extremely long cold season. So that means that we have to heat here for a very long time. Because we are heating with firewood, we have to prepare a lot of wood, maybe you've noticed those huge stacks of it here in the garden. So that involves a relatively large amount of work. (...) And you've got the option of the garden. If you're not lazy then you'll also prepare a load of what I'd call quality food. We don't have to buy a single potato. At that, the girls take some home. In the greenhouse I grow cauliflowers, tomatoes, cucumbers, everything, naturally other things as well. So there's an advantage there. (Hanušovice region)

In this quote, the respondent explains that the time and physical work necessary for subsistence production is a burden you can manage only by not being lazy, but at the same time this work seems to have an important place in his daily routine and is not generally questioned. Here, he refers not only to saving money, but also connects his gardening work to obtaining quality food and sharing with his relatives.

These "soft" aspects of subsistence production came to light in several interviews: home renovations, preparing firewood and garden work were activities that were engaged in with friends, neighbours and family members. Working together around the house was an inherent part of family visits, binding families together over distances. Garden products and homeproduced food were considered something of a high symbolic value and quality, shared in exchange for help or given to departing visitors as a treat. Consequently, not having access to a garden was described as a disadvantage in terms of free-time activities and exposure to social control. Given the multiple meanings imposed on subsistence production, it would be interesting to further explore the interpretative frameworks and the significance different groups connect with these practices.

The findings concerning locality-based income, economising and subsistence production strategies also have some explanatory potential when it comes to the question as to why moving from the villages was usually not regarded as an attractive strategy to overcome precarious situations. Given the importance of local resources for coping strategies, such as house and property ownership, proximity to the forest and agricultural production sites, and social integration within the local community, migration would mean the need to develop new resources and to adjust or abandon established strategies and daily routines. Despite all the hardship respondents feel exposed to, the rural living environment was broadly perceived as being rather beneficial in terms of overall wellbeing. Here also, the value ascribed to contact with nature and the conviction of living in a comparatively healthy, quiet and safe neighbourhood, might play an important role. Thus, notably, hypothetical migration to an urban locality was often depicted as unthinkable. Urban life was usually imagined as a reduction in quality of life and sometimes linked to notions of insecurity, threat and stress. When considering migration at all, rather than conceiving it as an imminent need or desire, it was described as an hypothetical option for a distant or unspecified time in the future, for example for times of personal life changes such as old age, age-related health problems or one's own children moving away. 


\section{Mobility-based Strategies}

As our respondents stressed the necessity of commuting for everything, it is important to ask how people who are less mobile organise their travel. Two of the most relevant and sometimes interlinked mobility strategies which are available even to less-mobile respondents shall be explored here in detail.

\section{Lift giving}

When asked about their mobility arrangements, the respondents, amongst other factors, described various practices of lift giving. Asking neighbours or family members for lifts was an important practice for people without access to their own car, but sharing a ride was also used to reduce transport costs or avoid using inconvenient public transport. Again, local social capital was of high importance, as lift-giving was embedded in local social networks amongst neighbours and/or an integral part of systems of mutual help between family members. For example, asking for lifts was used within the context of the shopping strategies described above as a practice to further reduce the costs of food purchasing:

For example I have the option of making an arrangement with my boyfriend's mum and so we go shopping together. So we can do a really big shopping trip and buy food for the whole month, which definitely pays off more than walking to the supermarket every day and then carrying stuff home every day. But then again I wouldn't have the cost for the petrol, I would just walk, but in terms of the prices I have better options in Sumperk than here. It's more convenient to shop there, and we find more things. (Hanušovice region)

Besides such occasional shared trips with neighbours and family members, we also found local networks that regularly shared their cars to commute to work or drive their children to kindergarten, making mobility possible for members of this network without a driving licence or access to a car and lowering the costs for all network members. However, the widespread shift-work and the comparatively large distances between place of work and place of residence turn organising a regular and reliable car-pooling system into a particular challenge. Another barrier to using lifts can be linked to the difficulty of establishing reciprocity and fairness. The somewhat unclear line between ride sharing as a legitimate form of support between neighbours or family members and when it comes to be viewed as exploitation has potential for conflict, can produce uncomfortable dependencies and can lead to accusations of taking advantage of others. These ambiguities and the social costs accompanying lift taking and giving (which cannot be simply resolved by splitting petrol costs) might explain our finding that some respondents claimed that they could ask their neighbours for help with transport, but in fact made use of this possibility only sporadically and described it as a strategy in cases of emergency. The following example of a mother and daughter without driving licences shows how these implicitly perceived social constraints influence mobility strategies:

R1: They're decent people here, like, if you ask them, they'll give you a lift.

I: And just so as I'm in the picture, how often is it necessary to ask someone?

R1: We don't do it often. We prefer to carry it ourselves. Like when I go to the job centre tomorrow, then I'll do my shopping there, right? And we've got a shop here, so I'll buy the rest here. 
R2: If it's a big shopping trip, then once a month. And some people take advantage, they want to go all the time, don't they?

R1: Or here we've got my boyfriend's sister-in-law. And you know, we always ask her, she'll take us there. I don't take much advantage of it. We prefer to carry it on the bus.

(Zihle region)

Rather than risking being counted amongst those locals who cross the line and exploit others in order to get into the city, they travel by bus and carry bags or use the more expensive local shop, taking into account the lower spatial mobility and higher expenses for food. The dilemma of supporting as against exploiting your neighbours and family (and the efforts that are needed to negotiate the moving line between both extremes) should be taken into consideration when arguing for strengthening self-help and sharing economies in peripheral regions.

\section{Rationalisation of tra vel}

In the quote above, a second dominant mobility strategy can be identified: when everything is far away, access to goods and services is not only a question of available transport, but also a question of good planning and efficiency in travelling. The mother and daughter, who are dependent on public transport and have very limited financial resources, combine their food shopping with their monthly appointment at the job centre, to which they travel by bus. Especially for families with children and for respondents who are dependent on public transport, it was a big challenge to bring all the necessary travelling in line. Consequently, the ability to plan ahead, avoid unnecessary journeys and rationalise travel (e.g. by choosing a kindergarten or school which is on the way to work) proved to be a big advantage. As the following quote demonstrates, forgetting to fulfil a task during a trip to the city is not only an organisational problem, but generates extra costs, which are considered to be significant:

Well I take a notebook with me so that I don't forget anything. Because a bus journey there and back comes to 50 crowns. So I have to consider, if I forget something... then it's like I say... you have to think, don't you? And when there's more things to do, then you simply have to use your brain. Do as many things as you can on one day so that we don't have to make unnecessary trips, because it's like... well after all, we're unemployed. (Brumov-Bylnice region)

It was usual that children began travelling without their parents at a very young age on school busses to schools and kindergartens in neighbouring villages or towns. In some communities, the children were accompanied on the journey or met at the bus stop by a teacher. This service was regarded as a significant help to reduce the families' mobility costs in terms of time and money. It also especially increased the flexibility for women, who in most cases bear the main responsibility for child-care. As one woman put it, letting the children travel alone was perceived as one of the benefits of rural life: "Like in the town, I couldn't imagine that I'd do the same there..." (Zihle region). Another example can be seen in the mother and daughter quoted above, who repay their neighbour for giving them occasional lifts by getting her child ready for school and walking her to the bus stop, when the neighbour needs to leave the house early for shift work. In another case, female neighbours took turns driving their 
children to school or kindergarten. Neighbours and grandparents also played an important role in maintaining the complex family's mobility arrangements when unexpected problems occurred - e.g. the school bus being cancelled due to snow.

Bigger changes - e.g. a family member returning to the labour market after periods of absence - require renegotiating the family's mobility arrangements and division of labour. In one interview, a woman described her plans to re-enter the labour market after several years of maternity leave. As the positions available around her village are poorly paid, she decided to return to her previous job in a regional capital, situated about 1.5 hours by car from her home. Even though she says that she would be hypothetically open to moving to the town, she stresses that this is not a realistic option, as she would never be able to persuade her husband to leave the rural region they both grew up in, a fact she accepts and does not object to. Instead, she plans to commute to work on a weekly basis, sleeping over in the town two nights per week. During her absence, her husband would be responsible for the children. The grandmothers, who live in neighbouring communities, are regarded as a back-up in cases of emergency:

My husband [...] knows that he'll simply have to look after the kids. But then of course the kids come here at half past four. So it's just the case that you hang out with them for a while, give them their dinner and then they go to bed. So he manages it without any problems. He's not the type that wouldn't be able to look after the kids. And he understands that it's better if I'll have a job rather than sitting at home seven days a week, unemployed and unbearable, you know? And the time really does fly. On Monday morning I still get the kids ready, then Tuesday it's all day, and then I come home again on Wednesday evening. So if I come let's say at five, then I can already help him. So that's basically the way we've got it planned, we'll see how things are in a year's time. (Hanušovice region)

In the woman's narrative, her future arrangement is presented as a pragmatic solution beneficial and acceptable for both partners. But to make this point, she simultaneously downplays the time and effort her husband would need to invest in child care, stressing that she will be ready to support him even on her travel days, and preferring to accept life as a commuter rather than consider moving to her future place of work any further. The ambivalence in her narration well illustrates the dilemmas women can face when reacting to unfavourable or nonexistent regional employment possibilities by developing mobility-based income strategies that challenge established gender roles.

Proper planning, multi-purpose journeys, emergency fallback plans and efficient organisation of daily tasks are necessities faced by many families in urban areas as well. However, our findings suggest that, considering the distances involved, and in the absence of goods and the comparatively high costs of transport in terms of money and time, the ability to rationalise and plan out one's travel is particularly crucial in peripheral regions. In this respect, our findings also suggest that the entanglement of mobility patterns and gender roles in rural settings deserve further exploration. 


\section{Conclusion}

Our findings indicate that the various forms of disadvantage experienced by inhabitants of the rural regions under study, which are particularly vulnerable due to their poverty, level of education, unemployment, health and care-duties, are, in part, connected to and strongly influenced by the limited local opportunity structures that form an important context of their lives. We uncovered multiple intersections between individual and contextual factors of disadvantage. The limited job prospects, the need to commute to work as well as the shift operation, physical demands and the precarious labour conditions within the local labour market are the most visible restrictions of opportunities for the respondents, especially when they face limitations regarding their mobility and flexibility and/or have low levels of qualification. The absence and limited accessibility and affordability of services represent another important restriction, as well as the frequently mentioned limited free time activities and local community life. The interviews confirm the previously mentioned assumption of cumulative causation of disadvantage in rural areas. The multiplication of individual vulnerabilities in rural localities with poorly developed opportunity structures also strongly calls into question the provision of subsidised social housing and quarters for the poor in rural peripheries with weak labour markets. ${ }^{2}$

The account of diverse intersections between individual life circumstances and the contextual characteristics of the sites proved to be crucial to the analysis. Earlier studies have stressed the particular problems arising from the accumulation of individual mobility handicaps and limited local opportunities (Philip and Shucksmith 2003; Temelová et al. 2011; Shergold and Parkhurst 2012) and also the specific disadvantages of women in rural areas (Brown and Shafft 2003; Phillip and Shucksmith 2003; Plazinic and Jovic 2014). The results of our study indicate that mobility issues and gender issues are indeed significantly related to the impacts of opportunity structures in Czech peripheries. At the same time, the interviews show that there are other individual characteristics that intersect with opportunity structures and contribute to the accumulation of disadvantages and yet have received less attention. One of them is integration in local social networks that facilitate access to local opportunities and in some cases offer the possibility of alternative strategies. Another important aspect is household time management and the organization of daily activities. Households with more complex time regimes due to the various activities and/or caring duties of their members experience specific challenges in an environment of limited local opportunities. A potentially important perspective on living in peripheries thus seems to involve the geographic theorizing of time-space everyday activities based on the term "infrastructure of everyday life" (Jarvis 2005). This includes the overall context affecting the implementation of daily activities, whether in terms of spatial accessibility of institutions and social contacts, their temporal modes, or transport options. The infrastructure of everyday life as an outer frame forming

2 The mapping of social exclusion and ghettos in Czech municipalities revealed significant numbers of quarters for the poor in rural and peripheral areas (Čada et al. 2015); moreover, Matoušek (2013) demonstrated that in recent years, new council housing construction increased the supply of public housing particularly in small municipalities and in peripheral regions. 
the daily activities of individual residents can represent a significant limiting factor in rural peripheries, especially for households with more complex time regimes.

The significance of intersections between various factors in the resulting disadvantages corresponds with the sociological theory of intersectionality. Intersectionality understands social inequality as a result of the intersection of various biological and social categories, especially gender, race and class, and shows how the different systems of oppression and discrimination interconnect and multiply and produce specific patterns of discrimination and disadvantage (Choo and Ferree 2010). Linking theoretical considerations about the structure of local opportunities and rural poverty with the theory of intersectionality thus appears to be another potentially inspiring way of thinking that so far has received only little attention (Norris et al. 2010).

Taken together, a substantial proportion of our respondents experience the need to make considerable efforts in their every-day lives to access various opportunities to which they aspire or are obliged. On one hand, their individual needs can be poorly satisfied within the locality. On the other hand, they often have very limited spatial mobility and temporal flexibility. Consequently, their coping strategies are characterized by practices that either enhance their mobility or reduce the need to travel by making use of alternative local resources and economising. Local earning possibilities, kinship and other social networks, house and property-ownership and good planning and organisational skills proved to be important resources utilised by these strategies. Mobility strategies and moving away from the periphery were rarely considered by the respondents. Despite experiences of considerable economic and other difficulties, most of our respondents didn't have any specific plans to move and they even didn't represent moving as a potential strategy. However, the concept of local poverty pockets, trapping their inhabitants, unable to afford alternative housing (van Kempen 1997), seems to be too narrowly focused on housing market conditions to depict accurately the situation in the context of this study. The respondents' reflections on their decisions to stay in the periphery were not based on inability to find alternatives on the housing market, but rather on a complex set of social commitments, value patterns and affect-laden relationships towards the social and physical surrounding.

Many coping strategies proved to be highly dependent on resources that were closely linked to the respondent's particular place of residence in a rural community. When searching for strategies to combat rural poverty, social exclusion and spatial disadvantages, particular attention should be paid to already existing strategies and practices that make use of locallybased resources and might not be visible at first sight, or might appear unimpressive. At the same time, rural poverty and spatial disadvantages might be so invisible in part because of the ability and readiness of many rural residents to develop coping strategies, which are practiced outside of or in addition to formal supply systems such as welfare or the formal labour market. 


\section{References}

ALBER, Jens and Ulrich KOHLER. 2008. "Informal Food Production in the Enlarged European Union." Social Indicators Research 89(1): 113-127.

ALSTON, Margaret and Jenny KENT. 2009. "Generation X-pendable: The Social Exclusion of Rural and Remote Young People.” Journal of Sociology 45(1): 89-107.

BEETZ, Stephan. 2008 "Peripherisierung als räumliche Organisation sozialer Ungleichheit." Pp. 7-16 in Peripherisierung - eine neue Form sozialer Ungleichheit: Materialien der Interdisziplinären Arbeitsgruppe 21, edited by Eva BARLÖSIUS and Claudia NEU. Berlin: Brandenburgische Akademie der Wissenschaften.

BIRD, Kate, David HULME, Andrew SHEPHERD and Karen MOORE. 2002. "Chronic Poverty and Remote Rural Areas." Chronic Poverty Research Centre Working Paper 13.

BROWN, David L. and Kai A. SCHAFFT 2013. "Social Exclusion in Rural Areas of Central and Eastern Europe." Eastern European Countryside 9: 27-44.

CHOO, Hae Yeon and Myra Marx FERREE. 2010. "Practicing Intersectionality in Sociological Research: A Critical Analysis of Inclusions, Interactions, and Institutions in the Study of Inequalities." Sociological Theory 28(2): 129-149.

CLOKE, Paul and Mark GOODWIN. 1992. "Conceptualizing Countryside Change: From Post-Fordism to Rural Structured Coherence." Transactions of the Institute of British Geographers 17(3): 321-336.

COMMINS, Patrick. 2004. "Poverty and Social Exclusion in Rural Areas: Characteristics, Processes and Research Issues." Sociologia Ruralis 44(1): 60-75.

COTTER, David A. 2002. "Poor People in Poor Places: Local Opportunity Structures and Household Poverty." Rural Sociology 67(4): 534-555.

DUNCAN, Cynthia M. 1996. "Understanding Persistent Poverty: Social Class Context in Rural Communities." Rural Sociology 61(1): 103-124.

FISHER, Monica. 2005. "On the Empirical Finding of a Higher Risk of Poverty in Rural Areas: Is Rural Residence Endogenous to Poverty?" Journal of Agricultural and Resource Economics 30(2): 185-199.

GRAY, David, Jon SHAW and John FARRINGTON. 2006. "Community Transport, Social Capital and Social Exclusion in Rural Areas." Area 38(1): 89-98.

HÄMÄLÄINEN, Kari and Petri BÖCKERMAN. 2004. "Regional Labor Market Dynamics, Housing, and Migration." Journal of Regional Science 44(3): 543-568.

HAUKANES, Haldis. 2004. Velká dramata - obyčejné životy. Postkomunistické zkušenosti českého venkova. Prague: SLON.

HODGE, Ian, Jessica DUNN, Sarah MONK and Caroline KIDDLE. 2000. “An Exploration of 'Bundles' as Indicators of Rural Disadvantage." Environment and Planning A 32(10): 1869-1887.

JARVIS, Helen. 2005. "Moving to London Time, Household Co-ordination and the Infrastructure of Everyday Life." Time \& Society 14(1): 134-154.

JEHLIČKA, Petr, Tomáš KOSTELECKÝ and Joe SMITH. 2013. "Food Self-provisioning in Czechia: Beyond Coping Strategy of the Poor: A Response to Alber and Kohler's 'Informal Food Production in the Enlarged European Union' (2008)." Social Indicators Research 111(1): 219-234.

KEARNS, Ade, Kenneth GIBB and Daniel MACKAY. 2000. "Area Deprivation in Scotland: A New Assessment." Urban Studies 37(9): 1535-1559.

KUPISZEWSKI, Marek, Dušan DRBOHLAV, Philip REES and Helen DURHAM. 1999. "Vnitřní migrace a regionální populační dynamika - Česká republika na pozadí evropských trendů [Internal Migration and Regional Population Dynamics - Czech Republic in the Context of European Trends]." Geografie - sborník české geografické společnosti 104(2): 89-105. 
LOBAO, Linda M., Gregory HOOKS and Ann R. TICKAMYER. 2008. "Poverty and Inequality Across Space: Sociological Reflections on the Missing-Middle Subnational Scale." Cambridge Journal of Regions, Economy and Society 1(1): 89-113.

MEERT, Henk. 2000. "Rural Community Life and the Importance of Reciprocal Survival Strategies." Sociologia Ruralis 40(3): 319-338.

MUSIL, Jiří and Jan MÜLLER. 2008. "Vnitřní periferie v České republice jako mechanismus sociální exkluze [Inner Peripheries of the Czech Republic as a Mechanism of Social Exclusion]". Sociologický časopis/Czech Sociological Review 44(2): 321-348.

NORRIS, Adele N., Anna ZAJICEK and Yvette MURPHY-ERBY. 2010. "Intersectional Perspective and Rural Poverty Research: Benefits, Challenges and Policy Implications.” Journal of Poverty 14(1): $55-75$.

OSTI, Giorgio. 2010. "Mobility Demands and Participation in Remote Rural Areas." Sociologia Ruralis 50(3): 296-310.

OUŘEDNÍČEK, Martin, Petra ŠPAČKOVÁ and Marie FEŘTROVÁ. 2011. “Změny sociálního prostředí a kvality života v depopulačních regionech České republiky [Changes in Social Milieu and Quality of Life in Depopulating Areas of the Czech Republic]." Sociologický časopis/Czech Sociological Review 47(4): 777-803.

PÉNZES, János. 2013. “The Dimensions of Peripheral Areas and Their Restructuring in Central Europe.” Hungarian Geographical Bulletin 62(4): 373-386.

PETRICK, Martin and Peter WEINGARTEN. 2004. "The Role of Agriculture in Central and Eastern European Rural Development: An Overview”. Pp. 1-20 in the Role of Agriculture in Central and Eastern European Rural Development: Engine of Change or Social Buffer? Studies on the Agricultural and Food Sector in Central and Eastern Europe, edited by Martin PETRICK and Peter WEINGARTEN. Halle: IAMO.

PHILIP, Lorna J. and Mark SHUCKSMITH. 2003. "Conceptualizing Social Exclusion in Rural Britain." European Planning Studies 11(4): 461-480.

PLAZINIĆ RANKOVIĆ, Biljana and Jadranka JOVIĆ. 2014. "Women and Transportation Demands in Rural Serbia." Journal of Rural Studies 36: 207-218.

POLANYI, Karl. 1944. The Great Transformation. New York: Farrar and Rinehart.

REIMER, Bill. 2004. "Social Exclusion in a Comparative Context.” Sociologia Ruralis 44(1): 76-94.

ROSCIGNO, Vincent J. and Martha L. CROWLEY. 2001. "Rurality, Institutional Disadvantage, and Achievement/Attainment." Rural Sociology 66(2): 268-292.

ROSCIGNO, Vincent J., Donald TOMASKOVIC-DEVEY and Martha CROWLEY. 2006. "Education and the Inequalities of Place." Social Forces 84(4): 2121-2145.

SHERGOLD, Ian and Graham PARKHURST. 2012. "Transport-Related Social Exclusion amongst Older People in Rural Southwest England and Wales.” Journal of Rural Studies 28(4): 412-421.

SHUCKSMITH, Mark. 2004. "Young People and Social Exclusion in Rural Areas." Sociologia Ruralis 44(1): 43-59.

SHUCKSMITH, Mark, Stuart CAMERON, Tanya MERRIDEW and Florian PICHLER. 2009. "Urban-Rural Differences in Quality of Life Across the European Union.” Regional Studies 43(10): 1275-1289.

SHUCKSMITH, Mark and Lorna PHILIP. 2000. "Social Exclusion in Rural Areas: A Literature Review and Conceptual Framework." Report for the Scottish Executive Central Research Unit.

SIKORA, Ewa. 2007. "Youth from Rural Communities: Social Inequalities in Access to Education." Eastern European Countryside 13: 111-129.

SLACK, Tim. 2010. "Working Poverty across the Metro-Nonmetro Divide: A Quarter Century in Perspective, 1979-2003.” Rural Sociology 75(3): 363-387. 
SPOOR, Max. 2013. "Multidimensional Social Exclusion and the 'Rural-Urban Divide' in Eastern Europe and Central Asia." Sociologia Ruralis 53(2): 139-157.

TEMELOVÁ, Jana, Jakub NOVÁK, Lucie POSPÍŠILOVÁ and Nina DVOŘÁKOVÁ. 2011. "Každodenní život, denní mobilita a adaptační strategie obyvatel v periferních lokalitách [Everyday Life, Daily Mobility and the Coping Strategies of People Living in Peripheral Localities]". Sociologický časopis/Czech Sociological Review 47(4): 831-858.

TICKAMYER, Ann R. and Cynthia M. DUNCAN. 1990. "Poverty and Opportunity Structure in Rural America." Annual Review of Sociology 16: 67-86.

VAN KEMPEN, Eva T. 1997. "Poverty Pockets and Life Chances: On the Role of Place in Shaping Social Inequality." American Behavioral Scientist 41(3): 430-449.

WEBER, Bruce, Leif JENSEN, Kathleen MILLER, Jane MOSLEY and Monica FISHER. 2005. "A Critical Review of Rural Poverty Literature: Is There Truly a Rural Effect?” International Regional Science Review 28(4): 381-414.

\section{Authors}

Josef Bernard works as a researcher at the Institute of Sociology, Czech Academy of Sciences. He focuses in particular on socio-spatial differentiation and its dynamics in urban and rural areas, social inequality issues and local government studies.

Contact: josef.bernard@soc.cas.cz

Anja Decker is a Ph.D. student at Institut für Volkskunde/Europäische Ethnologie, Ludwig-Maximilians-Universität Munich, a member of the International Ph.D. program 'Transformations in European Societies". Her research interests are societal transformation in Central Eastern Europe, anthropology of work and rural anthropology.

Contact: decker.anja@gmx.de

Renata Mikešová is a researcher at the Institute of Sociology, Czech Academy of Sciences and Ph.D. student at the Department of Social Geography and Regional Development at the Faculty of Science, Charles University, Prague. She is interested in voting behaviour, migration, social disadvantage, demographic changes and their impacts on regions and cities.

Contact: renata.mikesova@soc.cas.cz

Kateřina Vojtíšková is a researcher at the Institute of Sociology, Czech Academy of Sciences. She focuses on research and theory of social inequalities and issues related to public policy, regional development and citizens' participation.

Contact: Katerina.Vojtiskova@soc.cas.cz 